\title{
Coleopteren aus Circassien, gesammelt von Hans Leder im Jahre 1887,
}

beschrieben von E. Reitter in Mödling.

XI. Theil.*)

Nachträge.

807. Cryphalus Lederi n. sp. Brevis, subparallelus, niger, brevissime fulvo-hispidulus, antennis, articulo primo et clava nigris exceptis, testaceis, pedibus brunneis, tarsis dilutioribus, antennarum clava ovali, distincte articulata, funiculo triarticulato, mandibulis ferrugineis, capite subgloboso thorace valde angustiore, antice arcuatim subrugose punctato et fulvosubvilloso, in medio foveola punctiformi impressa, postice alutaceo, haud punctato; prothorace coleopteris haud angustiore, longitudine vix latiore, antrorsum valde angustato, laterilus pone medium fortiter rotundato, supra convexo, dorso in quinque series valde tuberculato, seriebus omnibus arcuatis utrinque postice sensim magis abbreviatis, tribus anticis paullo subtilioribus distantibus, posticis brevibus majoribus magis approximatis, postice et lateribus sat fortiter sed minus profunde punctato, basi haud marginato; elytris thorace haud duplo longis, parallelis, convexis, subtiliter subseriatim punctatis et seriatim setulosis, interstitiis parce subtiliter punctatis et brevissime parceque subsetulosis, setulis subsquamaeformibus, punctis striarum et interstitiarum subaequalibus. L o n g. $1.3 \mathrm{~mm}$.

Nur dem Glyptoderus alni Lindem. ähnlich, aber sehr kurz gebaut, die Flügeldecken sind nur $1 \frac{3}{4}$ mal so lang als der Halsschild, die Punktstreifen undeutlich, viel feiner, nicht in die Quere gezogen, nirgends Querrunzeln bildend, der Halsschild hat einen ähnlichen dreieckigen Höckerflecken, dieser Höckerfleck beschränkt sich blos auf den vorderen Theil der Scheibe, die Höckerquerreihen sind, namentlich die kurzen in der Mitte, äusserst gross und so entwickelt, wie bei keiner sonst bekannten europäischen Art. Die Fühler sind schwarz, nur die Fühlergeissel ist gelb gefärbt, die letztere nur aus 3 Gliedern bestehend, hiervon das erste grösser, kugelig, die beiden anderen kleiner und schwach quer, dagegen die Keule durch 4 Ringeln aus 5 Theilen bestehend, ihre Nahtlinien gerade verlaufend.

*) X. Theil: Wien. Ent. Ztg. 1889, pag. 63.

Wiener Entomologische Zeitung, VIII. Jahrg., 3. Heft (31. März 1889). 
Des Gozis hat in der Rev. d'Ent. 1885, pag. 278 ganz richtig bemerkt, dass Glyptoderus Eichh. nur als Gruppenname von Cryphalus betrachtet werden könne. Nach meiner Wahrnehmung hat eben die Fühlerkeule einen Ring mehr, wo (sowie bei Cryphalus s. st.) die Geissel nur 4 Glieder zeigt und einen Ring weniger (Glyptoderus), wenn die Geissel aus 5 Gliedern besteht. Zudem ist das letzte Glied der Geissel bei Glyptoderus gegen die Spitze verbreitert und könnte fast schon zur Keule gezählt werden.

Zwei Exemplare klopfte Leder von dürren Astzäunen in Circassien.

Herr Louis Bedel hat in seinen Coléoptères du bassin de la Seine: Rhynchophora, pag. 398 der Gattung Cryphalus noch ein neues Subgenus: Taenioglyptes einverleibt. Die Gattung Cryphalus umfasst nun folgende Subgenera:

1. Die Fühlergeissel besteht aus 5 Gliedern; die Keule länglich. (Glyptoderus Eichh.)

Trypophloeus Fairm.

2. Die Fühlergeissel besteht aus 4 Gliedern; die Keule oval. a) Die Nähte der Fühlerkeule sind sehr stark gebogen. Ernoporus Thoms.

b) Die Nähte der Füllerkeule sind transversal, fast geradlinig.

๙) Augen nicht ausgerandet.

Cryphalus s. st. ${ }^{*}$ )

ß) Augen vorn ausgerandet.

Taenioglyptes Bed.**)

3. Die Fühlerkeule besteht nur aus 3 Gliedern; Keule kurz oval.

Cryphalops Reitt. ${ }^{* * *}$ )

Anmerkung zu Hydraena dentipalpis Reitt. (Wien. Ent. Zeit. 1888, pag. 143.)

Das a. a. O. beschriebene Exemplar ist ein o. Dem $q$, wovon sich noch 2 Stücke vorgefunden haben, fehlt die zahnartige Bildung auf der Innenseite des letzten Tastergliedes; es stimmt jedoch sonst in allen Theilen mit dem ö überein. Das letzte Tasterglied ist an der Spitze dunkel gefärbt, wodurch diese Art von den nahe verwandten ebenfalls leicht $\mathrm{zu}$ unterscheiden ist.

*) Hierher: Cr. tiliae Panz. (Ratzeburgi Ferr.)

**) Hierher: Cr. piceae Ratz., numidicus Eichb., abietis Ratz.

***) Hierher: Cr. Lederi Reitt. 


\section{$2 \mathrm{BHL}$ Biodiversity Heritage Library}

Reitter, Edmund. 1889. "Coleopteren aus Circassien, gesammelt von Hans LEDER im Jahre 1887. XI. Theil." Wiener entomologische Zeitung 8, 93-94. https://doi.org/10.5962/bhl.part.20030.

View This Item Online: $\underline{\text { https://www.biodiversitylibrary.org/item/42656 }}$

DOI: https://doi.org/10.5962/bhl.part.20030

Permalink: https://www.biodiversitylibrary.org/partpdf/20030

\section{Holding Institution}

Smithsonian Libraries

\section{Sponsored by}

Smithsonian

\section{Copyright \& Reuse}

Copyright Status: NOT_IN_COPYRIGHT

This document was created from content at the Biodiversity Heritage Library, the world's largest open access digital library for biodiversity literature and archives. Visit BHL at https://www.biodiversitylibrary.org. 